\author{
Military Technical College \\ Kobry Elkobbah, Cairo, \\ Egypt.
}

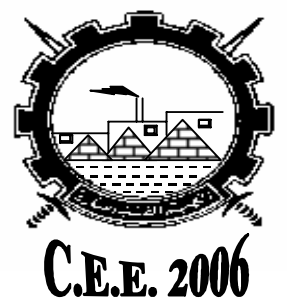

$3^{\text {rd }}$ International Conference

On

Chemical \& Environmental

Engineering

\title{
REMOVAL OF COPPER(II) IONS FROM AQUEOUS EFFLUENT USING MELAMINE-FORMALDEHYDE-DTPA RESIN IN A FIXED-BED UP-FLOW COLUMN
}

\author{
Baraka A. A.*., Hall P. J *anoM. J. Heslop*
}

\begin{abstract}
Melamine-Formaldehyde- diethylenetriaminepentaacetic acid (MF-DTPA) resin was prepared as a new adsorbent for removing heavy metals from wastewater effluents. In the synthesis process, the chelating agent diethylenetriaminepentaacetic acid (DTPA) anchored to melamine via amide covalent bond during melamineformaldehyde condensation reaction in aqueous acidic medium. Resin characterisation using FT-IR, elemental analysis and $\mathrm{N}_{2}$ gas adsorption (BET) were carried out to determine DTPA functionality and porosity. Water regain factor was also determined to find out hydrophilic character of the resin. Removal of $\mathrm{Cu}(\mathrm{II})$, as a representative of heavy metals, from synthetic wastewater using fixed-bed column packed with MF-DTPA grains was studied considering bed height, influent concentration and influent flow rate as controlling factors. The Thomas model was used to fit the adsorption data and its constants were evaluated. The Bed Depth Service Time (BDST) model was conducted to predict the service time of columns operated at different influent concentration and influent flow rates. It was found that DTPA successfully anchored to MF during resin matrix formation. The produced resin is hydrophilic (water regain 72\%) and its surface area is $162 \mathrm{~m}^{2} \mathrm{~g}^{-1}$ with neglected micro-porosity. DTPA is suggested to be present as 0.93 mmole per gram solid resin. The removal of $\mathrm{Cu}$ (II) ion using fixed-bed mode column packed with MF-DTPA grains kinetically follows Thomas model. BDST model was found to fit the results and applicable for scaling up the system with dynamic capacity, $N_{\circ}=7232 \mathrm{mg} \mathrm{ml}^{-1}$ and active zone, $Z_{\circ}=2.2 \mathrm{~cm}$.
\end{abstract}

The MF-DTPA resin has a potential for removal of heavy metals from wastewater effluents.

\section{KEY WORDS}

Heavy metals; copper(II) ion removal, adsorption; MF-DTPA resin; Thomas model; BDST model.

\footnotetext{
* Department of Chemical and Process Engineering University of Strathclyde, Glasgow G1 1XJ, UK.
} 


\section{NOMENCLATURE}

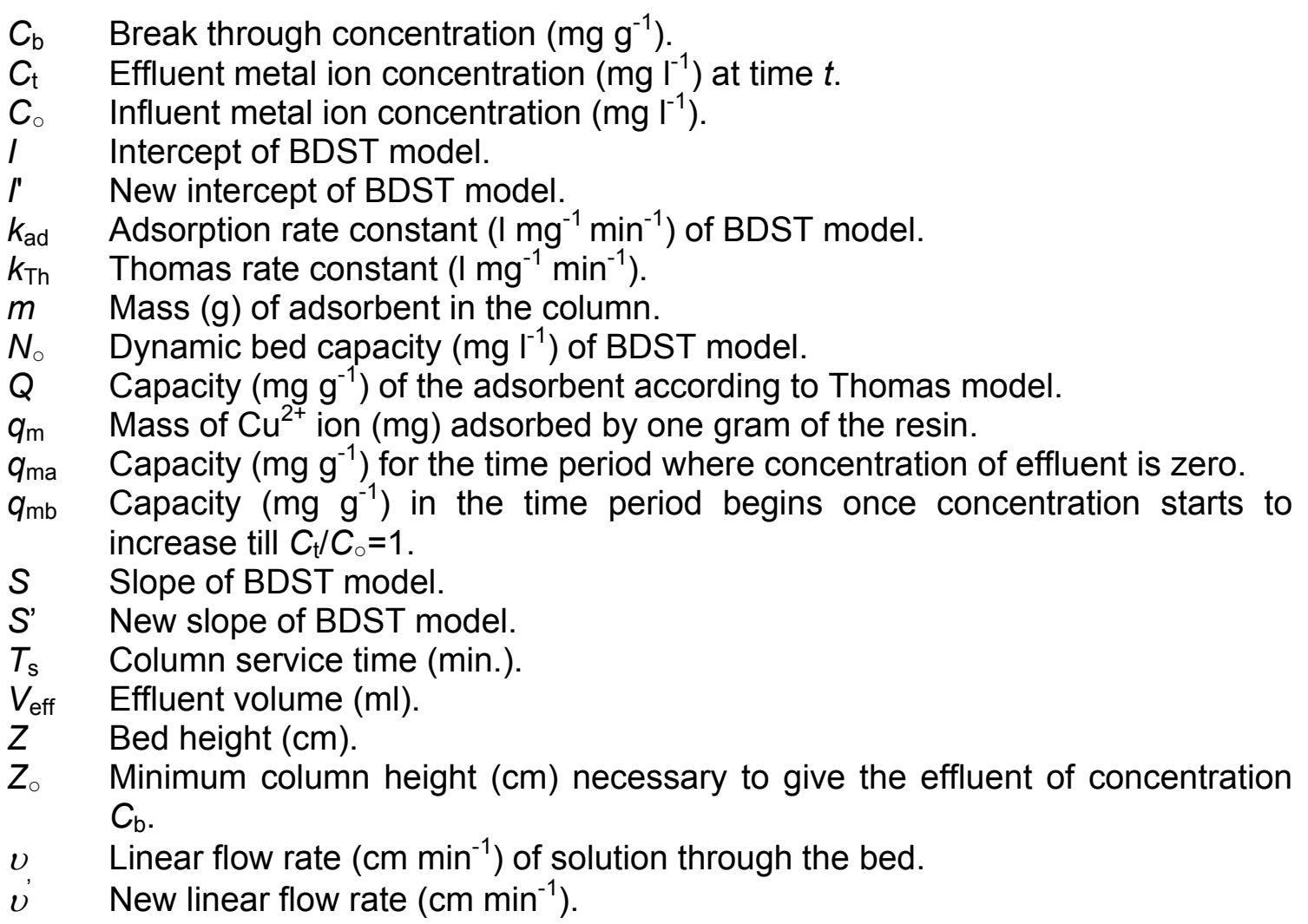

\section{INTRODUCTION}

The discharge of heavy metal ions into ecosystem has shown rapid increase due to increase of industrial activities such as electroplating, paper production, electronic industries, etc. The need to remove heavy metals from wastewater effluents originate from its high toxicity. Developing cost-effective and highly efficient material able to reduce the heavy metal concentrations in wastewater effluents to acceptable regulation standards is of great importance. Synthetic resin can contribute in the heavy metal remediation by introducing efficient adsorbents. This efficiency means simply, cheap, high capacity and reusability of the resin which has to be employed with reliable technique. Packed-column operation is the most practical and economical way to remove contaminants, including heavy metals, from wastewater effluents. There were many studies concerned with heavy-metal adsorption using fixed-bed column system and most of this used biosorping materials, different types of active carbon, and different inorganic sorbents [1-6]. In this work, melaminformaldehyde-diethylenetriaminepentaacetic acid (MF-DTPA) chelating resin was synthesised via anchoring DTPA to melamine by the reaction of carboxyl group of DTPA with a primary amine group of melamine forming covalent amide bond during MF matrix formation. The granular form of the formed resin was used in column mode for removal of $\mathrm{Cu}^{2+}$ ion from flowing synthetic wastewater. 


\section{THEORY}

\section{Resin Preparation and Characterization}

Melamine, formaldehyde and DTPA were mixed in pre-acidified water. By heating the mixture, methylolation reaction takes place ,catalyzed by acid, where $-\mathrm{NH}_{2}$ groups of melamine react with formaldehyde to give methylol $\left(-\mathrm{NH}-\mathrm{CH}_{2} \mathrm{OH}\right)$ groups. The methylol groups condense upon further heating and form methylene and ether bridges [7]. Anchoring of DTPA to the forming MF resin matrix occurs by reaction of carboxylic groups of DTPA with amine groups of melamine where amide covalent bonds are formed [8-11]. MF resin sample was prepared under same conditions as a reference for MF-DTPA. Characterization of MF-DTPA resin was carried out using IR spectrometry, CHNO elemental analysis for MF-DTPA and MF resins and BET method analysis for MF-DTPA resin.

\section{Column Adsorption Studies}

\section{(Analyses and Modelling of Column Adsorption Process)}

Adsorption within a packed bed column is a continuous process where mass transfer of the solute $\left(\mathrm{Cu}^{2+}\right)$ occurs from the mobile phase $\left(\mathrm{Cu}^{2+}\right.$ solution) to the solid phase (the MF-DTPA resin bed). The experimental capacity $q_{m}$ is the mass of $\mathrm{Cu}^{2+}$ ion in mg adsorbed by one gram of the resin and can be calculated using the following equation:

$$
q_{m}=q_{m a}+q_{m b}
$$

where $q_{\mathrm{ma}}$ is the capacity $\left(\mathrm{mg} \mathrm{g}^{-1}\right)$ for the time period where concentration of effluent is zero and can be calculated using the following equation:

$q_{m a}=\frac{V_{\text {eff }} C_{o}}{1000 m}$

where $V_{\text {eff }}$ the effluent volume $(\mathrm{ml}), C_{\circ}$ is the influent metal ion concentration $\left(\mathrm{mg} \mathrm{l}^{-1}\right)$ and $m$ is the mass of adsorbent in the column $(\mathrm{g}) . q_{\mathrm{mb}}$ is the capacity $\left(\mathrm{mg} \mathrm{g}^{-1}\right)$ in the time period begins once concentration starts to increase till $C_{t} / C_{0}=1$ and can be calculated by considering the area above the breakthrough curve.

The data collected in continuous mode studies was used to determine the kinetic parameters using Thomas model which is widely used for column studies $[2,5]$. Thomas model has the following linearized expression;

$\ln \left(\frac{C_{o}}{C_{t}}-1\right)=\frac{1000 k_{T h} Q_{m}}{v}-\frac{k_{T h} C_{o} V_{\text {eff }}}{v}$

where $C_{\mathrm{t}}\left(\mathrm{mg} \mathrm{l}^{-1}\right)$ is the effluent metal ion concentration at time $t . k_{\mathrm{Th}}$ is the Thomas rate constant $\left(\mathrm{I} \mathrm{mg}^{-1} \mathrm{~min}^{-1}\right), Q\left(\mathrm{mg} \mathrm{g}^{-1}\right)$ is the capacity of the adsorbent, $m(\mathrm{~g})$ is the mass of adsorbent in the column, $v\left(\mathrm{ml} \mathrm{min}^{-1}\right)$ is the linear flow rate. The model constants, $Q$ and $k_{\mathrm{Th}}$, can be determined from the plot of $\ln \left(C_{\circ} / C_{\mathrm{t}}-1\right)$ versus time $t$, $t=V_{\text {eff }} / v$, by calculating slope and intercept. 
Practical full-scale adsorption column can be designed based on results obtained from laboratory-scale adsorption column when appropriate mathematical model adequately verifies these results. The Bed Depth Service Time (BDST) model proposed by Bohart and Adams[12] and linearized by Hutchins [13] and McKay and Bino[14] is the simplest and rapid approach to describe column adsorption process. This model ignores the intra-particle mass transfer and external film resistances and considers, only, the solute reaction to the adsorbent vacant sites to control the adsorption process $[3,4]$. The model relates column service time, $T_{\mathrm{s}}$ ( $\min$.), and bed depth, $Z$ (cm):

$$
\mathrm{T}_{\mathrm{s}}=\frac{\mathrm{N}_{\mathrm{O}} \mathrm{Z}}{\mathrm{C}_{\mathrm{o}} \mathrm{v}}-\frac{1}{\mathrm{k}_{\mathrm{ad}} \mathrm{C}_{\mathrm{O}}} \ln \left(\frac{\mathrm{C}_{\mathrm{o}}}{\mathrm{C}_{\mathrm{b}}}-1\right)
$$

The slope and intercept of equation (4) are as follows:

$$
\begin{aligned}
& \text { slope }=\mathrm{S}=\frac{\mathrm{N}_{\mathrm{O}}}{\mathrm{C}_{\mathrm{O}} \mathrm{v}} \\
& \text { intercept }=\mathrm{I}=\frac{1}{\mathrm{k}_{\mathrm{ad}} \mathrm{C}_{\mathrm{O}}} \ln \left(\frac{\mathrm{C}_{\mathrm{O}}}{\mathrm{C}_{\mathrm{b}}}-1\right)
\end{aligned}
$$

where $N_{\circ}\left(\mathrm{mg} \mathrm{l}^{-1}\right)$ is the dynamic bed capacity, $C_{\circ}\left(\mathrm{mg} \mathrm{g}^{-1}\right)$ is solute initial concentration, $v\left(\mathrm{~cm} \mathrm{~min}^{-1}\right)$ is the linear flow rate of solution through the bed, $C_{\mathrm{b}}(\mathrm{mg}$ $\left.\mathrm{g}^{-1}\right)$ is the pre-specified break through concentration, and $k_{\mathrm{ad}}\left(\mathrm{I} \mathrm{mg}^{-1} \mathrm{~min}^{-1}\right)$ is the adsorption rate constant. Hence, this equation can be used to calculate the adsorption service time, $T_{\mathrm{s}}$, of a column of bed height $Z$, given the parameters $N_{\circ}$, and $k_{\mathrm{ad}}$ which must be determined from laboratory experiments.

Three bed heights at the same flow rate and influent concentration are sufficient to be experimentally carried out to establish BDST equation for column adsorbing system [15]. Setting $T_{\mathrm{s}}=0$ and solving Eq (4) for $Z$ gives

$\mathrm{Z}_{\mathrm{o}}=\frac{\mathrm{v}}{\mathrm{N}_{\mathrm{o}} \mathrm{k}_{\mathrm{ad}}} \ln \left(\frac{\mathrm{C}_{\mathrm{o}}}{\mathrm{C}_{\mathrm{b}}}-1\right)$

where $Z_{\circ}(\mathrm{cm})$ is the minimum column height necessary to give the effluent of concentration $C_{\mathrm{b}}$.

From equation (4), prediction of service time, $T_{\mathrm{s}}$, for different flow rates, $v$, can be conducted by modifying the slope according to the next relation $[15,16]$ :

$$
S^{\prime}=S \frac{v}{v^{\prime}}
$$


where $S^{\prime}$ and $v^{\prime}$ are the new slope and new flow rate respectively. The intercept part of equation (4) need not to be modified as $k_{\text {ad }}$ is not affected by changing flow rates. Also, prediction of service time, $T_{\mathrm{s}}$, for different influent concentration, $C_{\circ}$, can be conducted by modifying the slope and intercept according to the next relations respectively $[15,16]$ :

$S^{\prime}=S \frac{C_{0}}{C_{0}{ }^{\prime}}$

$I^{\prime}=\left(\frac{C_{o}}{C_{0}^{\prime}}\right) \frac{\ln \left(\frac{C_{o}^{\prime}}{C_{b}}-1\right)}{\ln \left(\frac{C_{o}}{C_{b}}-1\right)}$

where $C_{\circ}{ }^{\prime}$ and $I$ ' are the new influent concentration and new intercept respectively.

\section{Column Regeneration Study}

Efficient regeneration and reuse of an adsorbent is an important criterion to reduce the cost of removal process. For successful regeneration process, eluting agent should not deteriorate the adsorbent so much. In this work regeneration was carried out using EDTA solution as this agent is strong chelating agent and can elute $\mathrm{Cu}^{2+}$ forming a stable soluble $\mathrm{Cu}(\mathrm{II})$-EDTA complex.

\section{EXPERIMENTAL}

\section{Preparation of Resin}

Analytical grade of Melamine 99\% (Aldrich), formaldehyde 38\% (BDH), DTPA and EDTA (Sigma) were used in this work. For all solution preparation deionised water was used. The MF-DTPA resin was prepared as follows; 0.01 mole Melamine (1.26 $\mathrm{g})$, Formaldehyde $(2 \mathrm{ml})$, and 0.003 mole DTPA $(1.31 \mathrm{~g})$ were added into $5 \mathrm{ml}$ acidified water $(\mathrm{pH} 1.5)$. The vial containing the mixture was vigorously agitated to guarantee complete homogeneity of slurry formed. The tightly closed vial then was put in preheated oven at $120{ }^{\circ} \mathrm{C}$. Under this condition, a monolith solid gel was formed within about 20 minutes. The product was left for extra 30 minutes at the same temperature for more curing. The vial then removed and left on bench over night. The solid monolith resin then was ground and sieved. The grains (size=710:355 $\mu \mathrm{m}$ ) were washed in $100 \mathrm{ml}$ deionised water 5 times at ambient temperature using shaker at $150 \mathrm{rpm}$, each wash process lasted for 30 minutes. These washing processes were for removing acidity and any other remaining reactants (melamine, DTPA, and Formaldehyde).

\section{Resin Characterization}

\section{IR and Elemental Analysis Measurements}

For the IR analysis, Perkin-Elmer Spectrum one FT-IR spectrometer was used for IR spectra analysis using $\mathrm{KBr}$ discs with a suitable amount of MF and MF-DTPA resins. Analysis was made in the range 400 to $4000 \mathrm{~cm}^{-1}$. Perkin-Elmer Series II CHNS/O Analyser model 2400 was used for elemental analysis of dried MF and MF-DTPA samples. 


\section{Porosity}

Micromeritics ASAP $2405 \mathrm{~N}$ adsorption analyzer was used for conducting nitrogen adsorption/desorption isotherms at $77.4 \mathrm{~K}$ to determine porosity characteristics of the MF-DTPA resin. An MF-DTPA Sample was freeze dried to remove all gelling water without distorting the pores or shrinkage of the matrix. The porosity parameters were derived by BET analysis method.

\section{Metal Ion Continuous Adsorption}

\section{Metal Ions Solutions}

Chloride salt was used for $\mathrm{Cu}^{2+}$ ion, $\mathrm{CuCl}_{2} \cdot 2 \mathrm{H}_{2} \mathrm{O}$ (May \& Baker Ltd). $\mathrm{Cu}^{2+}$ standard stock solution of $1000 \mathrm{ppm}(1 \% \mathrm{HCl})$ was prepared where standard diluents were freshly prepared from it for adsorption experiments and $\mathrm{pH}$ was adjusted to $5-5.5$ using concentrated and diluted $\mathrm{HCl}$.

\section{Column Studies}

A Perkin-Elmer atomic absorption spectrometer 3100 with multi-element hollow cathode lamp and an air-acetylene burner was used for determining the effluent $\mathrm{Cu}^{2+}$ ion concentrations. The wave-length, $324.8 \mathrm{~nm}$, applied was that recommended by the manufacturer. Hanna Instrument $\mathrm{pH}$ model $\mathrm{H} 18519$ was used for $\mathrm{Cu}^{2+}$ solution $\mathrm{pH}$ measurement. The continuous removal system is composed of influent solution reservoir, resin-packed bed glass column; effluent solution reservoir and peristaltic pump as shown in Fig.1. The height and internal diameter of the glass column was 1.4 and $25 \mathrm{~cm}$ respectively. During packing the column with MF-DTPA resin, care was taken to avoid air entrapment to avoid channelling. Experiments were conducted varying fixed-bed height $(5,7$ and $9 \mathrm{~cm})$, flow rate $\left(3.2,5.5\right.$ and $\left.8.1 \mathrm{ml} \mathrm{min}^{-1}\right)$ and metal ion influent concentration $\left(20,30\right.$ and $\left.40 \mathrm{mg} \mathrm{l}^{-1}\right)$. The metal solution was upflow pumped through the fixed-bed using peristaltic pump at room temperature.

\section{Column Regeneration and Reuse}

Disposal of exhausted adsorbent loaded with heavy metal ions with out treatment causes another problem due to probable leach of these ions back into environment. This problem can be avoided by using one of elimination techniques such as elution, incineration and pyrolysis. The elution technique is the most preferred and so common allowing both recoveries of heavy metals at higher concentration and recycling of the adsorbent for subsequent use [5]. The recycling process is always accompanied by degradation of the adsorbent because of the deterioration phenomenon of active sites[6].

$\mathrm{Cu}^{2+}$ loaded MF-DTPA resin (under conditions: $\mathrm{Z}=7 \mathrm{~cm}, C_{\circ}=30 \mathrm{mg} \mathrm{g}^{-1}$ and $v=5.5$ $\left.\mathrm{ml} \mathrm{min}^{-1}\right)$ was eluted using EDTA solution $(0.01 \mathrm{M})$ with $v=5.5 \mathrm{ml} \mathrm{min}^{-1}$. Before elution, the resin was washed with $500 \mathrm{ml}$ distilled water to remove all $\mathrm{Cu}^{2+}$ solution may still present in the resin pores. After elution, the resin was washed again by 500 $\mathrm{ml}$ distilled water to remove all EDTA solution may still present in the resin pores. To examine the reuse, the same resin mass was used for second adsorption process under the same original adsorption conditions. The washing processes were carried out under the same flow conditions. 


\section{RESULTS AND DISSCUSION}

\section{General}

The produced resin is hydrophilic (water regain $72 \%$ ) and after grinding and sieving, $63.4 \%$ of original mass was found to be in the size range needed $(710: 355 \mu \mathrm{m})$.

\section{IR Spectra and Elemental Analysis}

The difference between the spectra of MF and MF-DTPA resins (not shown) implied the anchoring of DTPA to MF matrix such that peak at $1636 \mathrm{~cm}^{-1}$ is due to amide (carboxylic) carbonyl $\mathrm{C}=\mathrm{O}$ stretch, $690 \mathrm{~cm}^{-1}$ is due to amide $\mathrm{N}-\mathrm{H}$ out of plane and peak at $1390 \mathrm{~cm}^{-1}$ is due to Carboxylic In plane $\mathrm{O}-\mathrm{H}$ bend. From elemental analysis result, $36.7 \%$ of the resin mass is DTPA (0.93 mmole DTPA per gram of solid resin). Fig.2. gives a suggested structure of the MF-DTPA resin.

\section{Porosity (BET Characterization)}

Basic porosity parameters of MF-DTPA resin were found to be: BET surface area= $162 \mathrm{~m}^{2} / \mathrm{g}$, micropore area $\approx 0 \mathrm{~m}^{2} / \mathrm{g}$ and average pore diameter=95 $\AA$. $\mathrm{N}_{2}$ adsorption /desorption hysteresis loop ranges from 0.7 to $1\left(\mathrm{P} / \mathrm{P}_{\circ}\right)$ indicating open pore structure [17].

\section{Adsorption Process (Column Studies)}

Initially in the up-flow mode, when $\mathrm{Cu}^{2+}$ solution was introduced into the virgin resin bed, almost all $\mathrm{Cu}^{2+}$ ions were bonded to the chelating sites of the bottom layer of the resin, which can be imagined as a slice of the resin and can be recognised as adsorption-zone. As operation continued, this slice became saturated by $\mathrm{Cu}^{2+}$ ions and so the adsorption-zone moved up-word for the next slice. This ascending process is smooth and slices are merging not discrete. The process continued till reaching the top of the resin bed where the last slice became saturated and concentration of $\mathrm{Cu}^{2+}$ started to increase in the effluent till equalled initial influent concentration.

\section{Effect of Bed Height on Adsorption}

The breakthrough curves $\left(C_{t} / C_{\circ}\right.$ versus time) for $\mathrm{Cu}^{2+}$ ions adsorption on MF-DTPA resin packed column for bed heights 5,7 and $9 \mathrm{~cm}$ at $\mathrm{Cu}^{2+}$ solution flow rate of $5.5 \mathrm{ml}$ $\mathrm{min}^{-1}$ and initial concentration of $30 \mathrm{mg} \mathrm{l}^{-1}$ are shown in Fig.3. From curves we can notice that break-point, $T_{\mathrm{b}}\left(C_{\mathrm{t}} / C_{0}=0.1\right)$ and exhaustion time $\left(C_{t} / C_{0}=1\right)$ increased as bed height increased which means an increase in column service time. The $\mathrm{Cu}^{2+}$ ion experimental adsorption capacity of MF-DTPA, $q_{\mathrm{m}}$, significantly increased with height increase $(27.6,32.3$ and $33.4 \mathrm{mg} / \mathrm{g}$ for heights 5,7 and $9 \mathrm{~cm}$ respectively) and the solution volume treated, $V_{\text {eff, }}$ increased in the same manner $(1072,1788$ and $2530 \mathrm{ml}$ for heights 5,7 and $9 \mathrm{~cm}$ respectively) (Table 4). This behaviour is attributed to increase of the amount of resin (more chelating sites become available for adsorption).

\section{Effect of Initial Concentration on Adsorption}

The effect of influent concentration $\left(20,30\right.$ and $\left.40 \mathrm{mg} \mathrm{l}^{-1}\right)$ on breakthrough curves for bed height $7 \mathrm{~cm}$ and flow rate $5.5 \mathrm{ml} \mathrm{min}^{-1}$ is shown in Fig.4. It can be noticed from the curves that as influent concentration increases, the break-point $T_{\mathrm{b}}\left(\mathrm{C}_{\mathrm{t}} / C_{0}=0.1\right)$ and exhaustion time $\left(C_{t} / C_{\circ}=1\right)$ were reached earlier. The results demonstrated that the increase in concentration is accompanied by increase in experimental adsorption 
capacity, $q_{\mathrm{m}},\left(29.2,32.3\right.$ and 33.3 for influent concentrations 20,30 and $40 \mathrm{mg} \mathrm{l}^{-1}$ respectively) whereas the solution volume treated, $V_{\text {eff }}$, shows a decrease (2475, 1788 and $1403 \mathrm{ml}$ for influent concentrations 20,30 and $40 \mathrm{mg} \mathrm{l}^{-1}$ respectively) (Table 4). This can be explained by considering that a higher influent concentration may saturate the MF-DTPA resin more quickly. The larger the influent concentration, the steeper the breakthrough curve due to increase of saturation rate, Fig.4. Hence, as influent concentration increases, $\mathrm{Cu}^{2+}$ ions loading rate increases so does the driving force for mass transfer (i.e. diffusion process is concentration dependent).

\section{Effect of Flow Rate on Adsorption}

As the sectional area of the column is uniform, the linear flow rate (which is considered in this work) is directly proportional to volumetric flow rate. The effect of different flow rates $\left(3.2,5.5,8.1 \mathrm{ml} \mathrm{min}^{-1}\right)$ on breakthrough curves for bed height of 7 $\mathrm{cm}$ and influent concentration $30 \mathrm{mg} \mathrm{g}^{-1}$ is shown in Fig.5. It can be noticed from the curves that as flow rate increases, the break-point, $T_{b},\left(C_{t} / C_{0}=0.1\right)$ and exhaustion time $\left(C_{t} / C_{0}=1\right)$ were reached earlier. The $\mathrm{Cu}^{2+}$ ion experimental adsorption capacity of MF-DTPA, $q_{\mathrm{m}}$, changed with flow rate $(48.5,32.3$ and $19.25 \mathrm{mg} / \mathrm{g}$ for flow rates $3.2,5.5$ and $8.1 \mathrm{ml} \mathrm{min}^{-1}$ respectively). Also, treated volume, $V_{\text {eff, }}$ increased as flow rate decreased (2212, 1788 and $1296 \mathrm{ml}$ for flow rates $3.2,5.5$ and $8.1 \mathrm{ml} \mathrm{min}^{-1}$ respectively) (Table 4). This behaviour may be attributed to predomination of axial dispersion over horizontal dispersion at higher flow rates which causes less time for $\mathrm{Cu}^{2+}$ ions to diffuse into the resin pores and this strongly supported by noting less steepness in breakthrough curve for the higher flow rate, Fig.5 [16].

Table 4. Experimental results of up-flow column adsorption considering bed height, influent concentration and influent flow rate

\begin{tabular}{|c|c|c|c|}
\hline$\left[Z(\mathrm{~cm}), C_{\circ}\left(\mathrm{mg} \mathrm{l}^{-1}\right), v\left(\mathrm{ml} \mathrm{min}^{-1}\right)\right]$ & $V_{\text {eff }}(\mathrm{ml})$ & $T_{\mathrm{b}}(\mathrm{min})$ & $q_{\mathrm{m}}\left(\mathrm{mg} \mathrm{g}^{-1}\right)$ \\
\hline$[5,30,5.5]$ & 1072 & 195 & 27.62 \\
\hline$[7,30,5.5]$ & 1788 & 320 & 32.26 \\
\hline$[9,30,5.5]$ & 2530 & 460 & 33.43 \\
\hline$[7,20,5.5]$ & 2475 & 450 & 29.2 \\
\hline$[7,40,5.5]$ & 1403 & 255 & 33.31 \\
\hline$[7,30,3.2]$ & 2212 & 660 & 48.49 \\
\hline$[7,30,8.1]$ & 1296 & 160 & 19.25 \\
\hline
\end{tabular}

\section{Thomas Model Analysis}

The Thomas model was applied to experimental results with respect to bed height, influent concentration and influent flow rate. For bed heights 5, 7 and 9 at flow rate of $5.5 \mathrm{ml} / \mathrm{min}$ and influent concentration of $30 \mathrm{mg} \mathrm{l}^{-1}$, data showed linearity with Thomas model as shown in Fig.6. Form Table 5 it can be noticed that Thomas rate constant, $k_{\mathrm{Th}}$, and capacity, $Q$, increased with bed height which means that increasing bed height has positive influence on process.

For $\mathrm{Cu}^{2+}$ ions influent concentrations 20,30 and $40 \mathrm{mg} \mathrm{l}^{-1}$ at flow rate of $5.5 \mathrm{ml} / \mathrm{min}$ and bed height of $7 \mathrm{~cm}$, data showed linearity with Thomas model as shown in Fig.7. With the increase of influent concentration Thomas rate constant, $k_{\text {Th }}$ did not give a trend but column capacity, $Q$, showed an increase which is in agreement with experimental capacity (Table 5). 
For influent flow rates $3.2,5.5$ and $8.1 \mathrm{ml} / \mathrm{min}$ at bed height of $7 \mathrm{~cm}$ and influent concentration of $30 \mathrm{mg} \mathrm{l}^{-1}$, data showed linearity with Thomas model as shown in Fig.8. Table 5 summarises corresponding Thomas parameters $k_{\mathrm{Th}}$ and $Q$. Thomas rate constant, $k_{T h}$, increased with flow rate whereas capacity decreased which in agreement with experimental capacity.

Generally, Thomas rate constant, $k_{\mathrm{Th}}$ is in the range of $1.3 \times 10^{-3} \mathrm{I} \mathrm{mg}^{-1} \mathrm{~min}^{-1}$ which is comparable with some other studies [5]. Thomas model estimated capacities, $Q$, are very comparable with experimental capacities which suggest good representation of the model to adsorption under up-flow conditions for MF-DTPA resin.

Table 5. Parameters predicted from Thomas model considering bed height, influent concentration and influent flow rate

\begin{tabular}{|c|c|c|c|}
\hline$\left[Z(\mathrm{~cm}), C_{\circ}\left(\mathrm{mg} \mathrm{l}^{-1}\right), v\left(\mathrm{ml} \mathrm{min}^{-1}\right)\right]$ & $k_{\mathrm{Th}}\left(\mathrm{I} \mathrm{mg}^{-1} \mathrm{~min}^{-1}\right)$ & $Q\left(\mathrm{mg} \mathrm{g}^{-1}\right)$ & $R^{2}$ \\
\hline$[5,30,5.5]$ & $1.17 \times 10^{-3}$ & 21.97 & 0.9748 \\
\hline$[7,30,5.5]$ & $1.21 \times 10^{-3}$ & 32.30 & 0.9766 \\
\hline$[9,30,5.5]$ & $1.25 \times 10^{-3}$ & 43.75 & 0.9800 \\
\hline$[7,20,5.5]$ & $1.50 \times 10^{-3}$ & 29.69 & 0.9593 \\
\hline$[7,40,5.5]$ & $1.32 \times 10^{-3}$ & 33.16 & 0.9702 \\
\hline$[7,30,3.2]$ & $9.13 \times 10^{-4}$ & 36.55 & 0.9923 \\
\hline$[7,30,8.1]$ & $1.42 \times 10^{-3}$ & 26.13 & 0.9847 \\
\hline
\end{tabular}

Correlation factor, $R^{2}$, is high which means good fit of data with the Thomas model.

\section{BDST Model Analysis}

From the breakthrough curves shown in Fig.3, BDST plots were determined for $C_{t} / C_{\circ}$ $=0.033,0.1,0.5$ and 0.9 as shown in Fig.9.

The BDST equations of these lines are as follows:

$$
\begin{array}{lll}
\mathrm{T}_{\mathrm{s}}=62.5 \mathrm{Z}-144.17 & \text { for } \mathrm{C}_{\mathrm{t}} / \mathrm{C}_{\circ}=0.033 & \left(\mathrm{R}^{2}=0.9995\right) \\
\mathrm{T}_{\mathrm{s}}=67.5 \mathrm{Z}-149.17 & \text { for } \mathrm{C}_{\mathrm{t}} / \mathrm{C}_{\circ}=0.1 & \left(\mathrm{R}^{2}=0.9995\right) \\
\mathrm{T}_{\mathrm{s}}=66.3 \mathrm{Z}-65.417 & \text { for } \mathrm{C}_{\mathrm{t}} / \mathrm{C}_{\circ}=0.5 & \left(\mathrm{R}^{2}=0.9999\right) \\
\mathrm{T}_{\mathrm{s}}=63.75 \mathrm{Z}-1.25 & \text { for } \mathrm{C}_{\mathrm{t}} / \mathrm{C}_{\circ}=0.9 & \left(\mathrm{R}^{2}=0.9988\right)
\end{array}
$$

The slopes are nearly the same for all lines which means, according to equation (3), that $N_{\circ}$ value did not change with bed height indicating that adsorption zone is moving up the column at a constant speed [3]. For $C_{t} / C_{\circ}=0.1, k_{\mathrm{ad}}$ was calculated using equation (4) and the minimum column height necessary to give effluent of concentration $C_{b}=3 \mathrm{mg} \mathrm{g}^{-1}, Z_{\circ}$, was also calculated using equation (5). These design parameters were found to be, $N_{\circ}=7232 \mathrm{mg} \mathrm{ml}^{-1}$ (correspond to $25.8 \mathrm{mg}$ per gram of solid resin), $k_{\mathrm{ad}}=4.91 \times 10^{-4} \mathrm{I} \mathrm{mg}^{-1} \mathrm{~min}^{-1}$ and $Z_{\circ}=2.2 \mathrm{~cm}$ according to BDST model. Correlation factor, $R^{2} \geq 0.9995$ which means good fit of data with the BDST model.

\section{Examining BDST Model with Influent Concentration and Flow Rate Conditions}

To examine the BDST model for practical application, a comparison of experimental service time and predicted service time according to BDST model with respect to influent concentration (at $C_{t} / C_{\circ}=0.1$, flow rate $5.5 \mathrm{ml} \mathrm{min}^{-1}$ and bed height of $7 \mathrm{~cm}$ ) and with respect to influent flow rate $\left(\right.$ at $C_{t} / C_{\circ}=0.1$, influent concentration $30 \mathrm{mg} \mathrm{g}^{-1}$ and bed height of $7 \mathrm{~cm}$ ) are given in Table 6. It is clear from the table the high match 
between experimental and predicted service times which suggest using this model for the purpose of scaling-up of the system.

Table 6. BDST model fitting with influent concentration condition and influent flow rate condition

\begin{tabular}{|c|c|c|}
\hline$\left[Z(\mathrm{~cm}), C_{\circ}\left(\mathrm{mg} \mathrm{l}^{-1}\right), v\left(\mathrm{ml} \mathrm{min}^{-1}\right)\right]$ & Experimental service time $(\mathrm{min})$ & $T_{\mathrm{S}}(\mathrm{min})$ \\
\hline$[7,20,5.5]$ & 450 & 485 \\
\hline$[7,30,5.5]$ & 320 & 324 \\
\hline$[7,40,5.5]$ & 252 & 243 \\
\hline$[7,30,3.2]$ & 660 & 663 \\
\hline$[7,30,8.1]$ & 160 & 172 \\
\hline
\end{tabular}

\section{Column Regeneration and Reuse}

About $1100 \mathrm{ml}$ of EDTA solution was accumulated after completed elution process of $\mathrm{Cu}^{2+}$ ion from loaded MF-DTPA dose. $\mathrm{Cu}^{2+}$ ion concentration of this solution was 48 $\mathrm{mg} \mathrm{l}^{-1}$. This means that removal from the total dose mass of the resin is 52.8 $\mathrm{mg}\left(\mathrm{Cu}^{2+}\right)$ which corresponds to $26.94 \mathrm{mg} \mathrm{g}^{-1}$. First adsorption process gave $q_{\mathrm{m}}=$ $32.26 \mathrm{mg} \mathrm{g}^{-1}$ and by calculation, the elution efficiency is $84 \%$. Fig.10 shows the elution cycle using EDTA solution. From the figure we can consider that most of $\mathrm{Cu}^{2+}$ ions were eluted in the fist 100 minutes which corresponds to 9.3 bed volumes. The number of bed volumes is an important parameter from design point of view as it suggests practical amount of eluting solution to be used.

Fig.11 shows first adsorption and second adsorption processes (after elution) with the same conditions $\left(Z=7 \mathrm{~cm}, C_{0}=30 \mathrm{mg} \mathrm{g}^{-1}\right.$ and $\left.v=5.5 \mathrm{ml} \mathrm{min}^{-1}\right)$. The second adsorption process has $T_{\mathrm{b}}=290$ minutes $\left(\right.$ at $\left.C_{\mathrm{t}} / C_{\circ}=0.1\right)$ which is less than that of first adsorption process by 30 minutes and $V_{\text {eff }}=1595 \mathrm{ml}$ which is less than that of first adsorption process by $165 \mathrm{ml}$. Adsorption capacity $q_{\mathrm{m}}$ was calculated and found to be $25.48 \mathrm{mg} \mathrm{g}^{-1}$ which means $79 \%$ of the first adsorption capacity. This decrease in performance can be attributed to deterioration of the resin because of loss of active sites which mainly occurred by hydrolysis of DTPA during adsorption process, elution and washing. This deterioration by hydrolysis is strongly suggested as $\mathrm{pH}$ of the effluent shows decrease. The deterioration is

\section{CONCLUSIONS}

Melamine-Formaldehyde-DTPA (MF-DTPA) resin was prepared as a new adsorbent for removing heavy metals from wastewater effluents. The MF-DTPA resin is formed by anchoring DTPA, through the amide bond, with MF matrix. IR and elemental analysis proved the success of anchoring DTPA to the MF matrix and DTPA present in resin was found to be $36.7 \%$. DTPA, as strong chelating agent, can chelate (chemi-sorp) heavy metals present in water effluent. The preparation conditions was $\mathrm{pH}=1.5$, a temperature of $120^{\circ} \mathrm{C}$, and a water content of $5 \mathrm{ml}$ with the stated amounts of reactants. The produced resin is hydrophilic (water regain $72 \%$ ) with surface area $=162 \mathrm{~m}^{2} \mathrm{~g}^{-1}$ and neglected micro-porosity. DTPA is calculated to be present as 0.93 mmole per gram solid resin. The removal of $\mathrm{Cu}^{2+}$ ion, as a representative of heavy metals, from an aqueous solution, by adsorption using up-flow method on fixed-bed 
packed column with MF-DTPA grains, was studied kinetically by Thomas model and results were found to fit the model for different bed heights, $\mathrm{Cu}^{2+}$ influent concentration and influent flow rate with correlation factor $R^{2} \geq 0.9593$. The Bed Depth Service Time (BDST) model was found to fit the experimental results as well with correlation factor $R^{2} \geq 0.9988$, hence being a suitable candidate for scaling up the fixed-bed up-flow column system for the purpose of removal of heavy metals using MF-DTPA resin as a packing adsorbent.

\section{REFERENCES}

[1] K. Vijayaraghavan, J. Jegan, K. Palanivelu, M. Velan, Chem. Eng. J. 106 (2005) 177-184.

[2] K. Vijayaraghavan, J. Jegan, K. Palanivelu, M. Velan, Chemosphere 60 (2005) 419-426.

[3] Danny C. K. Ko, John F. Porter, Gordon McKay, Chem. Eng. Sci. 55 (2000) 5819-5829.

[4] Z. Zulfadhly, M.D. Mashitah, S. Bhatia, Environ. Pollut.112 (2001) 463-470.

[5] Runping Han, Jinghua Zhang, Weihua Zou, Huijun Xiao, Jie Shi, Hongmin Liu, J. Hazard. Mater. xxx (2005) xxx-xxx.

[6] K. Vijayaraghavan, J. Jegan, K. Palanivelu, M. Velan, J. Hazard. Mater. B113 (2004) 223-230.

[7] E.Minopoulou, E.Dessipri, G.D.Chryssikos, V.Gionis, A.Paipetis, C.Panayiotou, Int. J. Adhes. Adhes. 23 (2003) 473-484.

[8] T.W.Graham Solomons, Organic Chemistry, sixth edition, John Wiley \& Sons, INC., 1996.

[9] Andreas Bernkop-Schnürch, Martina E. Krajicek, J. Controlled Release 50 (1998) 215-223.

[10] A.J.Varma, S.V.Deshpande, J.F.Kennedy, Carbohydr. Polym. 55 (2004) 77-93.

[11] Eram Sharmin, L.Imo, S.M.Ashraf, Sherif Ahmad, Prog. Org. Coat. 50 (2004) 47-54.

[12] G. S. Bohart, E. Q. Adams, J. Am. Chem. Soc., 42 (1920) 523-544.

[13] R. A. Hutchins, Am. J. Chem. Eng., 80 (1973) 133-138.

[14] G. McKay, M. J. Bino, Environ. Pollut., 66 (1990) 33-53.

[15] B.G. Prakash Kumar, Lima Rose Miranda, M. Velan, J. Hazard. Mater. B126 (2005) 63-70.

[16] V. Christian Taty-Costodes, Henri Fauduet, Catherine Porte, Yuh-Shan Ho, J. Hazard. Mater. B123 (2005) 135-144.

[17] Duong D. Do, Adsorption Analysis: Equilibria and Kinetics, Vol. 2, Imperial College Press, London, 1998. 


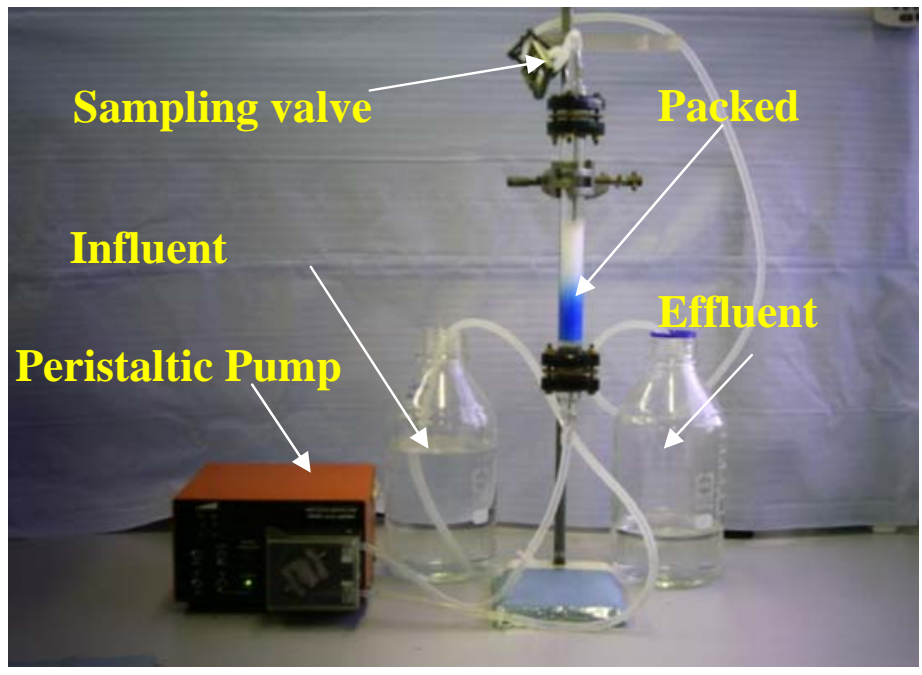

Fig.1. Experimental fixed-bed up-flow column setup.<smiles>[Y16]Nc1nc(NC(=O)N(CCN(CCN(CC(=O)O)CC(=O)O)CC(=O)O)CC(=O)O)nc(N[Y14]([Y14])([H])C)n1</smiles>

Fig.2. Suggested structure of MF-DTPA resin.

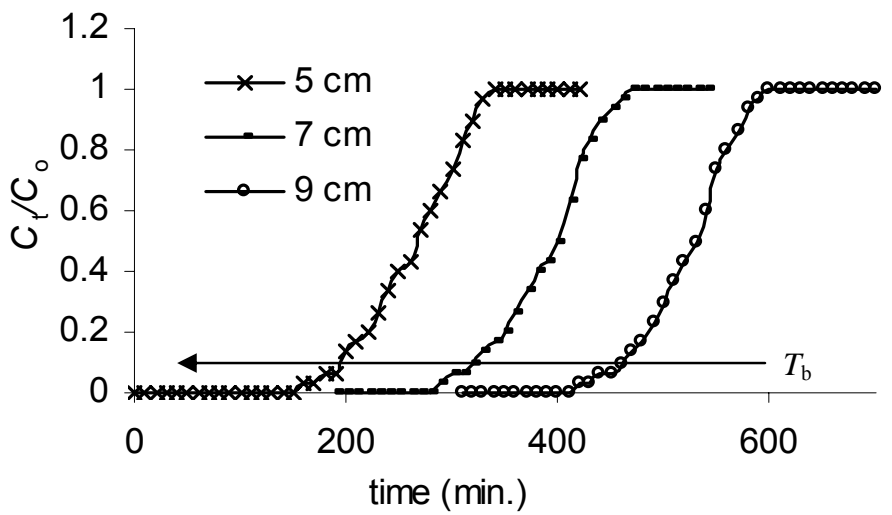

Fig.3. Breakthrough curves for $\mathrm{Cu}(\mathrm{II})$ adsorption on MF-DTPA resin at three different bed heights $\left(C_{0}=30 \mathrm{mg} \mathrm{l}^{-1}\right.$ and $\left.v=5.5 \mathrm{ml}\right)$. 


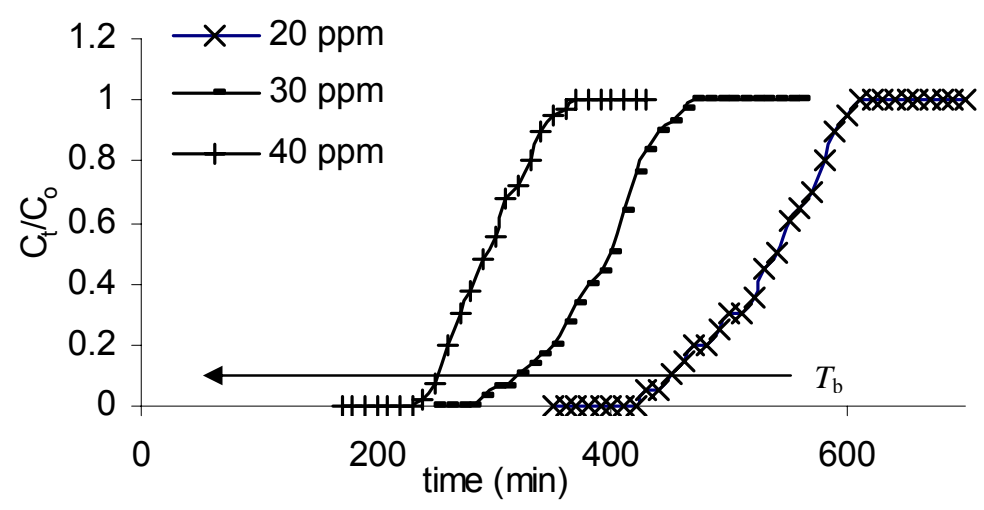

Fig.4. Breakthrough curves for $\mathrm{Cu}(\mathrm{II})$ adsorption on MF-DTPA resin at three different influent concentrations $(Z=7 \mathrm{~cm}$ and $v=5.5 \mathrm{ml})$.

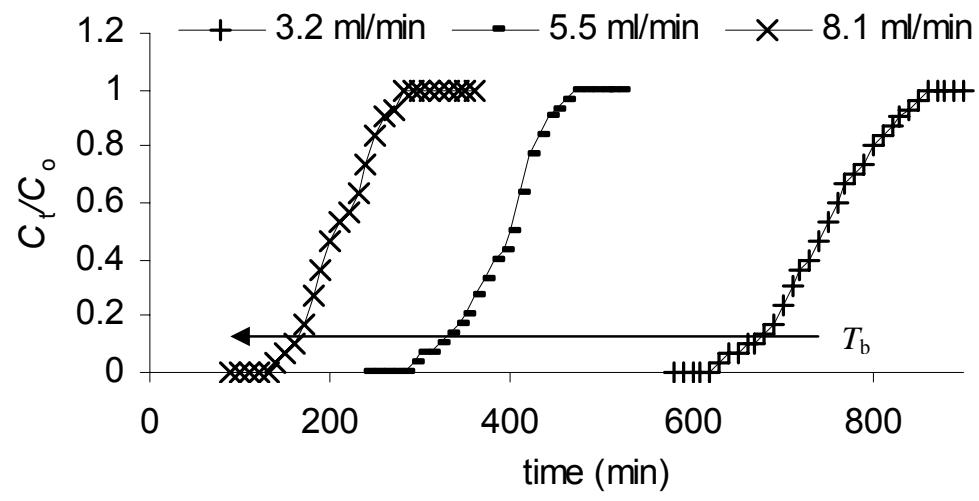

Fig.5. Breakthrough curves for $\mathrm{Cu}(\mathrm{II})$ adsorption on MF-DTPA resin at three different flow rates $\left(C_{\circ}=30 \mathrm{mg} \mathrm{l}^{-1}\right.$ and $\left.Z=7 \mathrm{~cm}\right)$.

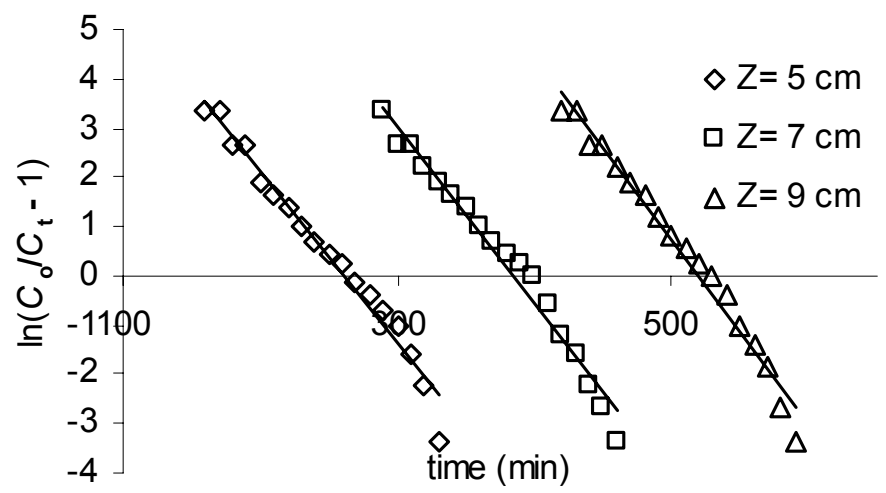

Fig.6. Thomas model fitting $\mathrm{Cu}(\mathrm{II})$ adsorption on MF-DTPA resin at three different bed heights $\left(C_{\circ}=30 \mathrm{mg} \mathrm{l}^{-1}\right.$ and $\left.v=5.5 \mathrm{ml}\right)$. 


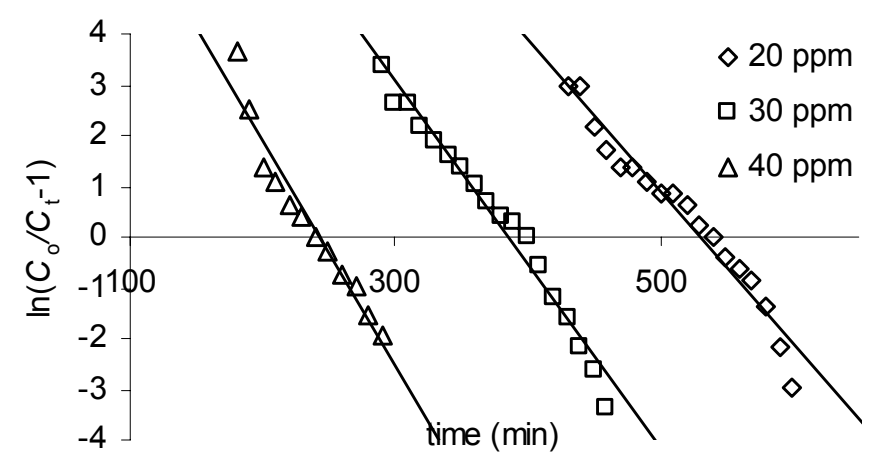

Fig.7. Thomas model fitting $\mathrm{Cu}(\mathrm{II})$ adsorption on MF-DTPA resin at different influent concentrations $(Z=7 \mathrm{~cm}$ and $v=5.5 \mathrm{ml})$.

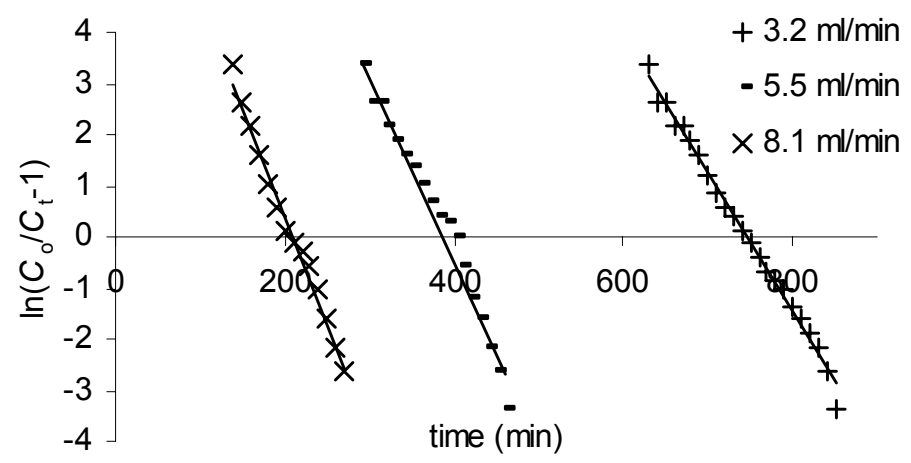

Fig.8. Thomas model fitting $\mathrm{Cu}(\mathrm{II})$ adsorption on MF-DTPA resin at different influent flow rates $\left(C_{0}=30 \mathrm{mg} \mathrm{l}^{-1}\right.$ and $\left.Z=7 \mathrm{~cm}\right)$.

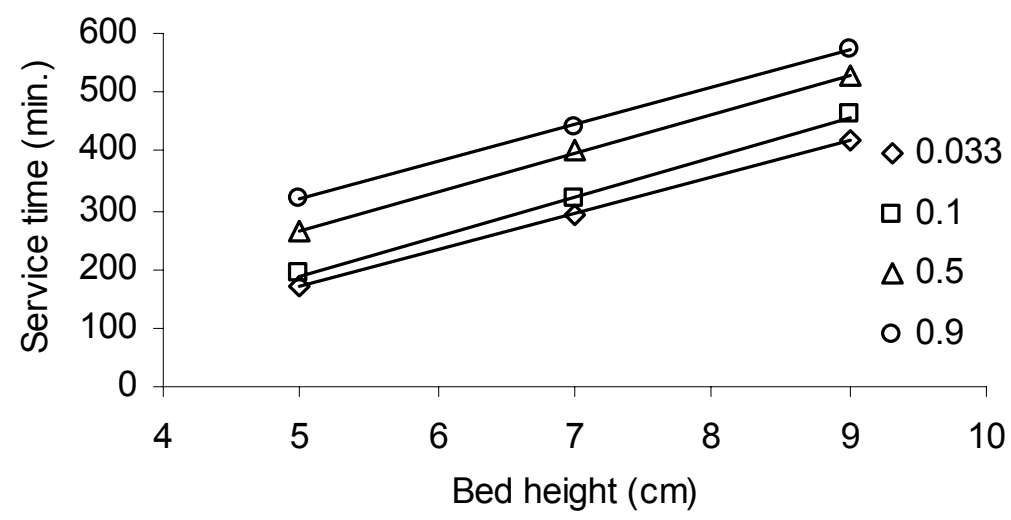

Fig.9. BDST plots at $C_{t} / C_{\circ}=0.033,0.1,0.5$ and 0.9 $\left(C_{\circ}=30 \mathrm{mg} \mathrm{l}^{-1}\right.$ and $\left.v=5.5 \mathrm{ml}\right)$. 


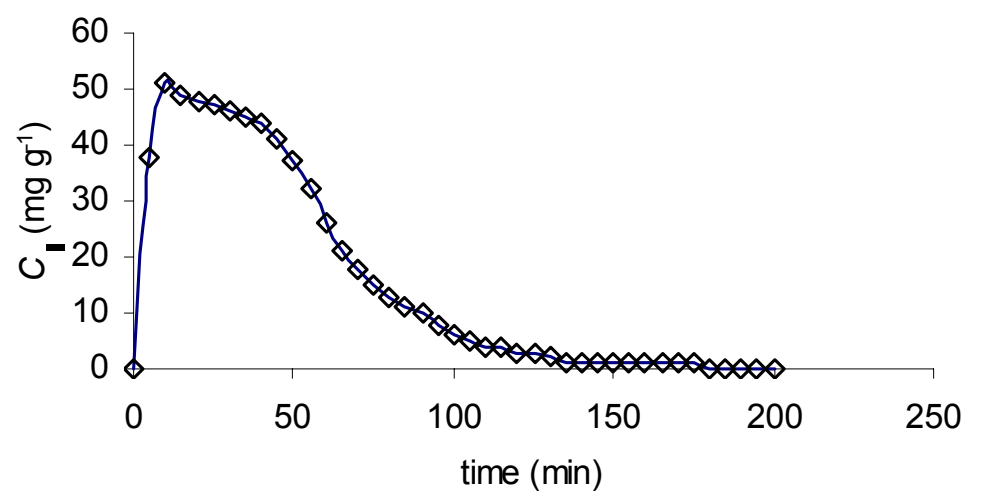

Fig.10. Time profile of $\mathrm{Cu}(\mathrm{II})$ concentration during elution of the resin with $0.01 \mathrm{M}$ EDTA solution.

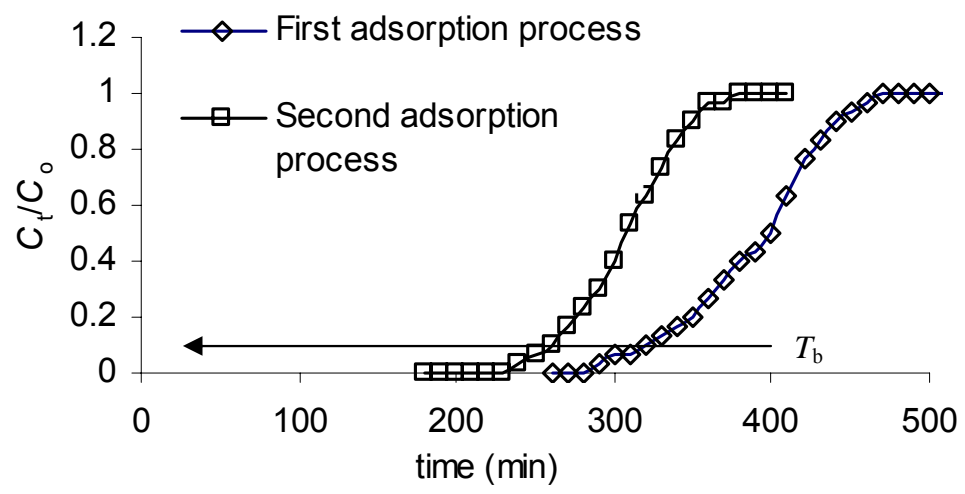

Fig.11. first and second adsorption breakthrough curves. 